\title{
In memory of Bernhard Schätz, long- time friend and SoSyM editor
}

\author{
Manfred Broy ${ }^{1} \cdot$ Bernhard Rumpe ${ }^{2}$
}

Published online: 22 January 2018

(c) Springer-Verlag GmbH Germany, part of Springer Nature 2018

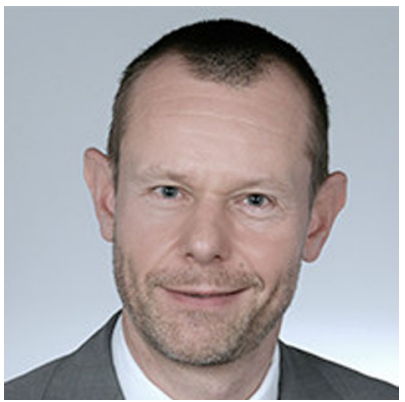

We were shocked about the passing of Dr. rer. nat. Dr. habil. Bernhard Schätz, also known as Barnie, on July 23rd, 2017. He finally lost the fight and passed away after a long battle against cancer. He was only 52 years old.

Bernhard Schätz was an extraordinary scientist and researcher. Completely free from any pursuit of self-promotion he devoted himself with great service to science and research. He had the extraordinary gift for excellent scientific work and yet the ability for an implementation in practical projects. His strength was not only his own scientific work, he could also inspire others for his subjects and thus create and lead his own research group. Especially noteworthy were his abilities to collaborate with practitioners and to achieve valuable results.

Bernhard Schätz came to the research group Software and Systems Engineering (SSE) of Manfred Broy only a few months after Manfred's start at the Technical University of Munich. Bernhard Rumpe had known Barnie already from his studies, but became a closer friend when collaborating intensively at the SSE group. From the beginning, Bernhard Schätz was at the core of the SSE group, working on central topics. He always was very careful and precise. He never gave a piece of text that came from his pen out of hand, if not with greatest care worded and scientifically sound. In 1998, he successfully completed his doctorate a pioneering work called "Ein methodischer Übergang von asynchron $\mathrm{zu}$ synchron kommunizierenden Systemen", tackling the combination of asynchronous high-level specifications to restricted synchronous implementations.

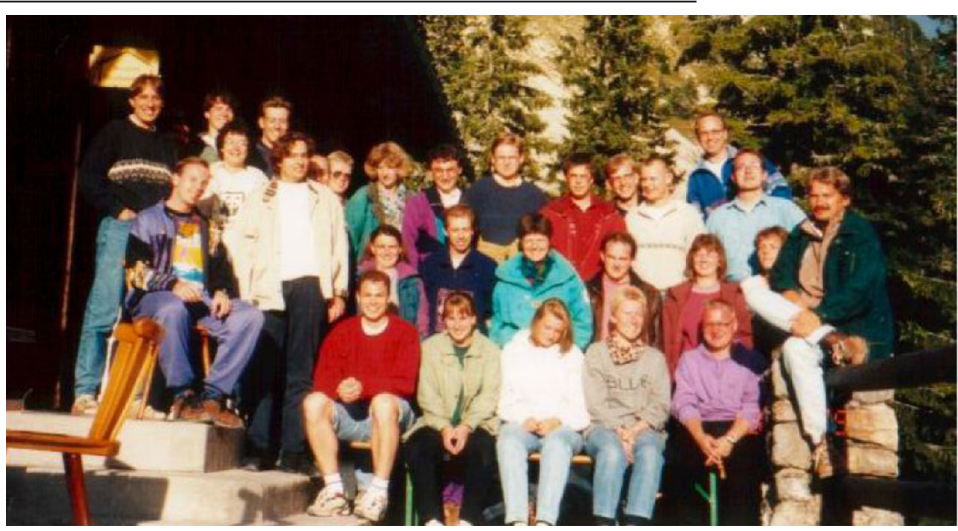

The Software and Systems

Engineering Group @ TU

Munich, led by Manfred Broy: at a three day seminar on scientific research in the Barbarahütte, in the Alps. Bernhard is 7th from left (grey shirt), 1995.

$凶$ Bernhard Rumpe bernhard.rumpe@sosym.org

Manfred Broy broy@in.tum.de

1 Institut für Informatik, Technische Universität München, Munich, Germany

2 RWTH Aachen University, Aachen, Germany
With his outstanding skills, both to the basic work, as well as his applied work, he was the driving force behind tool development in the SSE group. His work characterized many tools, starting with AutoFocus in its three incarnations, but had also impact on many other tooling infrastructures, such as MontiCore and MontiArc. 
He was also instrumental in founding Validas AG. He was a member of the board of Validas AG from the beginning until the end of his life, serving as a widely respected member of the Supervisory Board, and with his wise advise strongly championed the development of the company support.

Since he was completely dedicated to scientific work, he worked after finishing his doctorate towards a habilitation, which he successfully completed with a remarkable defence a few days before Christmas in 2009.
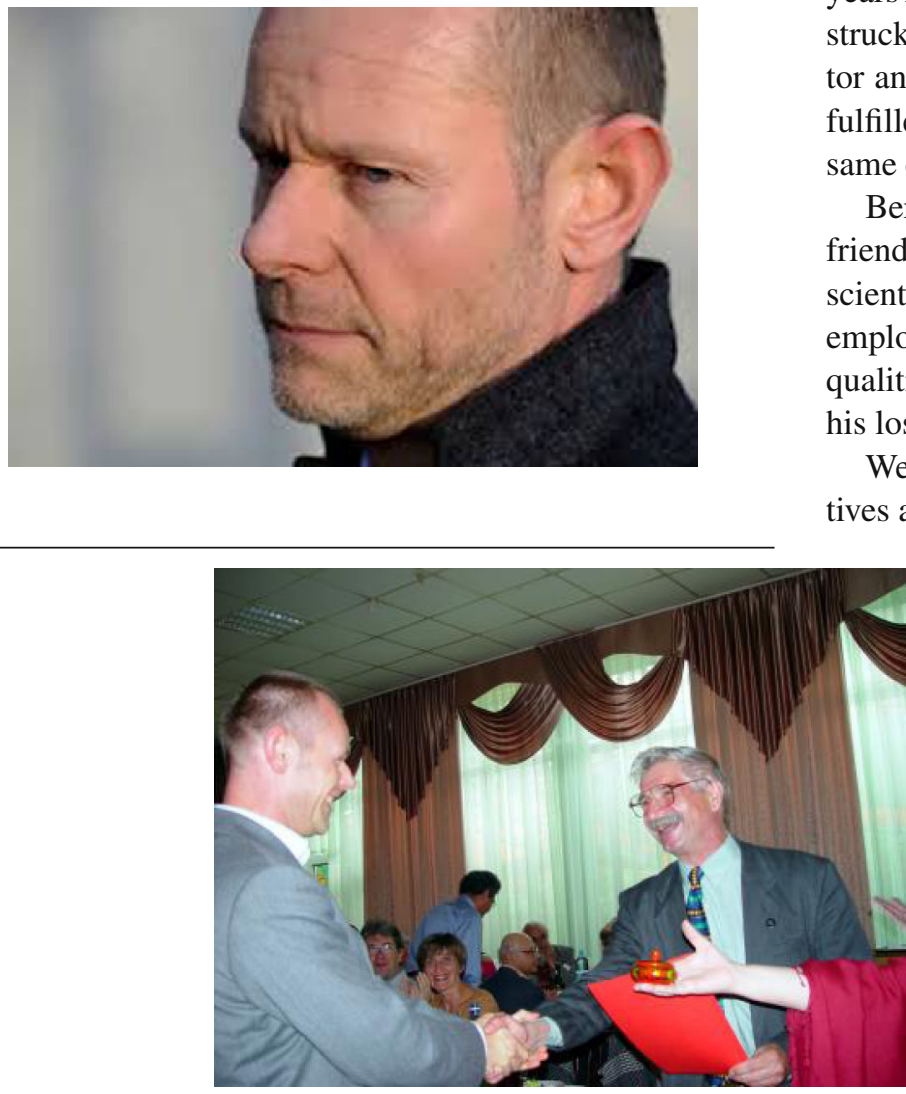

In the construction of the An-Institute fortiss of the Technical University of Munich, Bernhard Schätz was very enthusiastic from the beginning. He served as Scientific Director at fortiss with the research group on model-based development, where he was Vice-Managing Director. His efforts led to the structure and growth of the research institute within 5 years to a size of over 100 employees.

Bernhard Schätz also internationally received the highest respect. He was co-organizer of several events of the community, ranging from Dagstuhl events, over MBEES up to MODELS, where he chaired the industrial track in 2013. He was a long-standing member of the SoSyM Editorial Board from 2008 until his far too early death.

He was both valued for his great expertise, but also his deep insights into practical work and the numerous, successful projects he has has performed. His reliability was proverbial. You could always depend on his words. For exam-
Bernhard at the conference dinner of the

Andrei Ershov Fifth International

Conference «PERSPECTIVES OF

SYSTEM INFORMATICS», where

Bernhard was awarded the title "Mr.

Charming Smile", Novosibirsk, 2003

ple, he was consistently the reviewer who turned in his very accurate reviews first.

During the construction of the Center Digitization.Bayern, Bernhard Schätz was also vitally active in the task force to build the center. Again, capitalized from his comprehensive skills, but also with his vision and his deep understanding to make essential contributions.

Our horror was great, when we learned that Barnie suffered from a terrible, incurable cancer. But for a number of years he did not allow himself to be beaten by this disease. He struck out any offer to step down in his job or as SoSyM editor and get stronger in fighting his illness. Bernhard Schätz fulfilled his scientific tasks with the same discipline and the same enthusiasm as before. But, he finally could not escape.

Bernhard Schätz was a highly esteemed colleague, a friend, a valuable adviser, an internationally recognized scientist, but also an outstanding person, who dealt with employees and colleagues proving only the highest human qualities. He has done extraordinary. We will never overcome his loss.

We are in deep sadness to his family, his friends, his relatives and his colleagues.

Bernhard Schätz wrote 193 recorded research items (according to Researchgate) which have by the end of 2017 been cited more than 2500 times (according to Google Scholar). DBLP lists among others:

- 24 journal articles (5 of them in SoSyM)

- 84 conference and workshop papers, and

- 20 editorships

He curated an impressive list of 59 co-authors, showing his degree of esteem and respect among the community. One colleague once said that it was always fun arguing with him on scientific topics and issues, but you never could get him into a personal argument. We will miss the always fruitful discussions on topics of software engineering, modeling and specification using formal methods in highly practical projects.

Manfred Broy, Bernhard Rumpe 
More information can be found on:

- www4.in.tum.de/ schaetz

- www.fortiss.org

- dblp.uni-trier.de/pers/hy/s/Sch=auml=tz:Bernhard

- www.researchgate.net/profile/Bernhard_Schaetz/public ations

- http://de.linkedin.com/in/schaetz

- http://scholar.google.com/citations?user=dYCIKEIAAAAJ

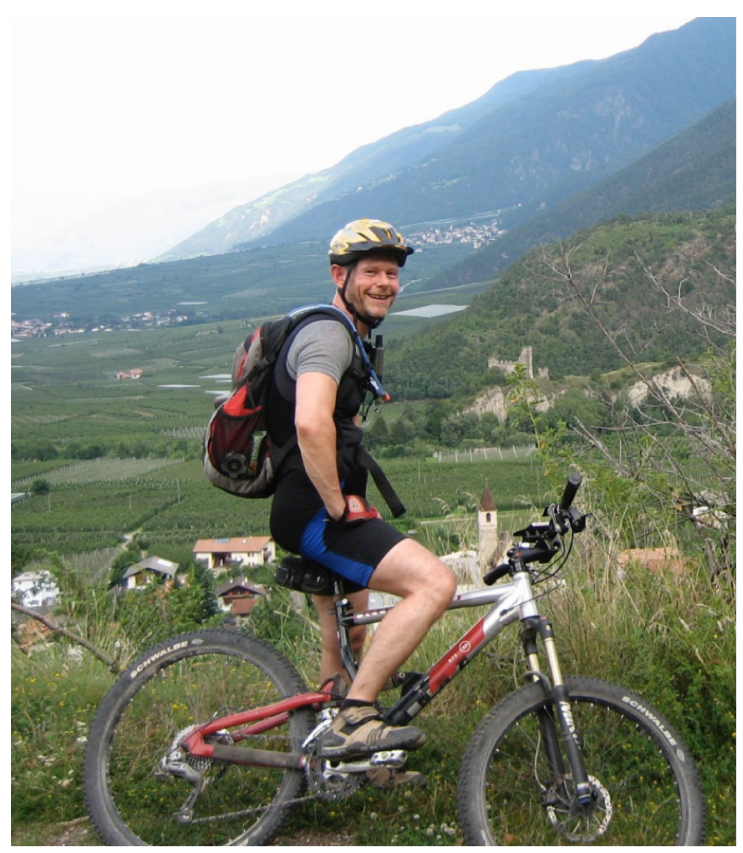

Bernhard in his element: One of his favourites was to hike in the mountains. The picture is donated by Bernhard's family, 2013 